Research Article

\title{
Development, implementation, and analysis of adverse drug reaction monitoring system in a rural tertiary care teaching hospital in Narketpally, Telangana
}

\author{
S. M. Shareef*, C. D. M. Naidu, Shrinivas R. Raikar, Y. Venkata Rao, U. Devika
}

\begin{abstract}
Department of Pharmacology, Kamineni Institute of Medical Sciences, Nalgonda, Telangana, India
\end{abstract}

Received: 22 June 2015 Accepted: 05 July 2015

*Correspondence to: Dr. S. M. Shareef, Email: drsharifshaik@gmail. com

Copyright: (C) the author(s), publisher and licensee Medip Academy. This is an openaccess article distributed under the terms of the Creative Commons Attribution NonCommercial License, which permits unrestricted noncommercial use, distribution, and reproduction in any medium, provided the original work is properly cited.

\begin{abstract}
Background: Adverse drug reactions (ADR) are the fourth leading cause of mortality and a great concern in therapeutics. Pharmacovigilance is more important in India as the health care system is inadequate with poor doctor-patient ratio, high incidence of self-medication, and presence of counterfeit drugs. The present study was conducted with the aim of analyzing the pattern of ADR occurring in a rural tertiary care hospital with a newly established pharmacovigilance center and to identify the most frequent ADRs, common drugs implicated and severity of reactions.

Methods: A non-interventional observational prospective study was conducted over a year. The red boxes for dropping the filled yellow ADR forms were installed in all the wards and outpatient departments. Additional information and missing data were obtained personally by either consulting the physician or through case sheets. Results: The most common class of drugs implicated in the causation of ADRs was antimicrobials $(52 \%)$, followed by drugs acting on the central nervous system. The most commonly observed ADRs were dermatological Type B reactions. The majority of the reactions belonged to possible or probable category, but no reaction was categorized as definite.

Conclusion: Dermatological reactions are the most common ADR occurring in our hospital and antimicrobials are the most common causative drugs. The reporting rate was adequate, and there is still a need for increasing the awareness and knowledge about ADR reporting system and pharmacovigilance for promoting the safe use of drugs.
\end{abstract}

Keywords: Pharmacovigilance, Adverse drug reactions, Tertiary care hospital

\section{INTRODUCTION}

Adverse drug reaction (ADR) is defined as any noxious, unintended, or undesirable effect of a drug which occurs at a dose normally used in man for prophylaxis, diagnosis or treatment of a disease, or for modification of physiological function. ${ }^{1}$ ADRs are the fourth leading cause of mortality and a great concern in therapeutics. ${ }^{2}$ At least one ADR has been reported to occur in $10-20 \%$ of hospitalized patients. ${ }^{3,4}$ ADRs have an immense economic burden on the patients as well as health care establishment. ${ }^{5}$ A study conducted in South India estimated the cost for management of ADRs in hospital as rupees 481 per day. ${ }^{6}$

Pharmacovigilance or ADR monitoring is an integral part of drug therapy, but not well-practiced in Indian hospitals. ${ }^{7}$ Pharmacovigilance is defined as the science and activities relating to detection, assessment, understanding, and prevention of ADRs or any other drug-related problem. ${ }^{6}$ The importance of pharmacovigilance can be understood by the fact that spontaneous reporting system has led to the withdrawal of some of the popular drugs like rofecoxib, rosiglitazone, and terfenadine. ${ }^{5}$ The Central Drugs Standard Control Organization under the aegis of Ministry of Health and Family Welfare, Government of India in collaboration with Indian Pharmacopoeia Commission, Ghaziabad has initiated nationwide Pharmacovigilance Program of India (PvPI). One of the targets of PvPI was to enroll all medical colleges in India as ADR monitoring centers by year $2014 .^{8}$

The present study was conducted with the aim of analyzing the pattern and severity of ADRs occurring in our institution, to identify the common drugs implicated in the causation of ADRs and to report the most common manifestations associated with these ADRs. 


\section{METHODS}

The present study was a non-interventional observational prospective study. It was conducted over a period of 1 year from January 2014 to December 2014. Before start of the study, introductory awareness lectures were organized by pharmacovigilance cell for all health care professionals, i.e., clinicians, postgraduate students, interns, and nursing staff. They were informed about the spontaneous ADR reporting system and the importance of pharmacovigilance to motivate the voluntary reporting of ADR. They were requested to report all observed adverse events and were also imparted training for filling the yellow forms. The yellow ADR reporting form was designed and made available at all nursing stations in the hospital for easy access of all the health care professionals. It included the information like patient initials, age, sex, and diagnosis, brief description of the reaction, name of suspected drug with route and frequency of administration, and the signature of the reporter. The red boxes for dropping the filled yellow ADR reporting forms were installed in all wards, emergency units, and outpatient departments in accordance with the guidelines of Pharmacovigilance program of India (PvPI). The red ADR boxes were checked daily for ADR forms. The collected forms were checked for completeness, and the missing data were obtained either by personally visiting the patient or going through the case sheets in case of doubt or consulting the treating physicians if necessary.

Causality assessment for relationship between the drug and reaction was established using World Health OrganizationUppsala Monitoring Center scale for causality assessment. ${ }^{9}$ The causality assessment was done by a Special Committee with two experts from pharmacology and a clinician. The ADRs were classified depending upon the organ system affected and also based on the type of reaction as per Rawlins and Thomson criteria. ${ }^{10}$ Classification system of Hartwig et al. was used to determine the severity of the reaction. ${ }^{11}$ The results were analyzed using descriptive statistics.

\section{RESULTS}

85 ADR forms were received by the pharmacovigilance cell from various clinical departments. Out of these, 81 were utilized for analysis and the rest were rejected due to their incompleteness in terms of reporters sign, patient initials, and drug name.

\section{Demographics}

Patients' age and gender were considered for evaluation. The patients were categorized into five age groups $(0-15$, $16-30,31-45,46-60$, and above 60 years). The male to female ratio was 1.13:1 (Table 1).

\section{Type of suspected ADR}

Out of 81 reactions, $76(93.82 \%)$ reactions were Type B (bizarre reactions or unexpected reactions) and $5(6.17 \%)$
Table 1: Demographic profile.

\begin{tabular}{|lc|}
\hline Parameter & Number $(\%)$ \\
\hline Total ADRs & 81 \\
\hline Male: Female & $1.13: 1$ \\
\hline $0-15$ years & $7(8.64)$ \\
\hline $16-30$ years & $28(34.56)$ \\
\hline $31-45$ years & $25(30.86)$ \\
\hline $46-60$ years & $13(16.04)$ \\
\hline$>60$ years & $8(9.87)$ \\
\hline
\end{tabular}

ADR: Adverse drug reaction

were Type A (augmented pharmacological effects - dosedependent and predictable) (Figure 1)

\section{Severity of the reported ADRs}

Of the total reactions, 66 (81.49\%) ADRs were non-serious and $15(18.51 \%)$ were classified as serious as they required either hospitalization or prolongation of hospital stay. Of the 15 serious ADRs, a single fatality has occurred (Figure 2).

\section{Causality assessment}

The causality was assessed as per WHO - UMC scale and $41(50.61 \%)$ ADRs were categorized as possible, whereas $40(49.31 \%)$ were categorized as probable. No reaction could be assessed as certain as rechallenge tests were not considered in view of patient safety.

\section{Drugs involved}

The most common group of drugs implicated in the ADRs were antimicrobials (46.91\%) followed by NSAIDS $(13.58 \%)$ and nutritional supplements $(8.64 \%)$. The most common antimicrobial was cephalosporin group and NSAID was diclofenac sodium. Iron sucrose was the nutritional supplement implicated in most of the reactions (Figure 3).

\section{Organ system involved}

The most frequently affected system was the skin (37.03\%), followed by the gastrointestinal tract $(17.28 \%)$ and then central nervous system $(12.34 \%)$. This was followed by the cardiovascular system $(6.17 \%)$, RS $(2.46 \%)$, and renal system (1.23\%) (Figure 4).

\section{Management of ADRs}

Of the 81 cases, 47 have recovered after the suspected drug was withdrawn. After giving symptomatic and supportive treatment, the suspected drug was continued in 29 cases and dose reduction was made in 5 cases. The above data emphasizes that there is no absolute need to discontinue the suspected drug in all the cases. Most of the reactions 


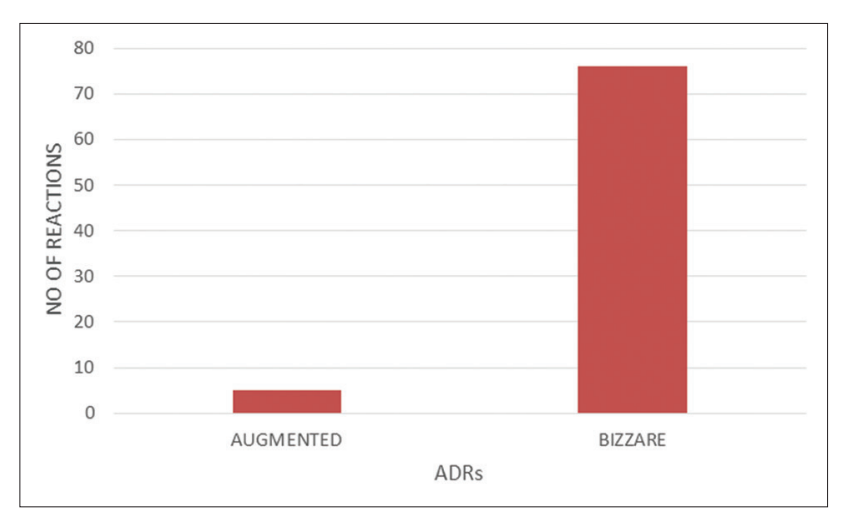

Figure 1: Type of adverse drug reactions.

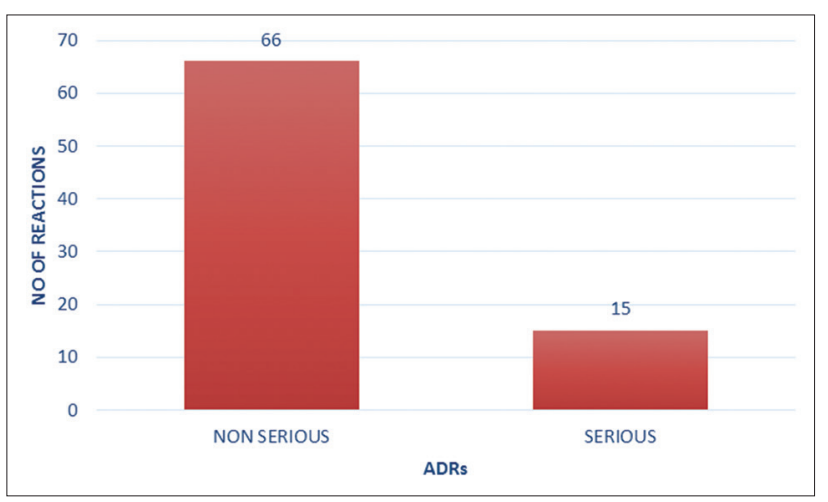

Figure 2: Serious versus non-serious adverse drug reactions.

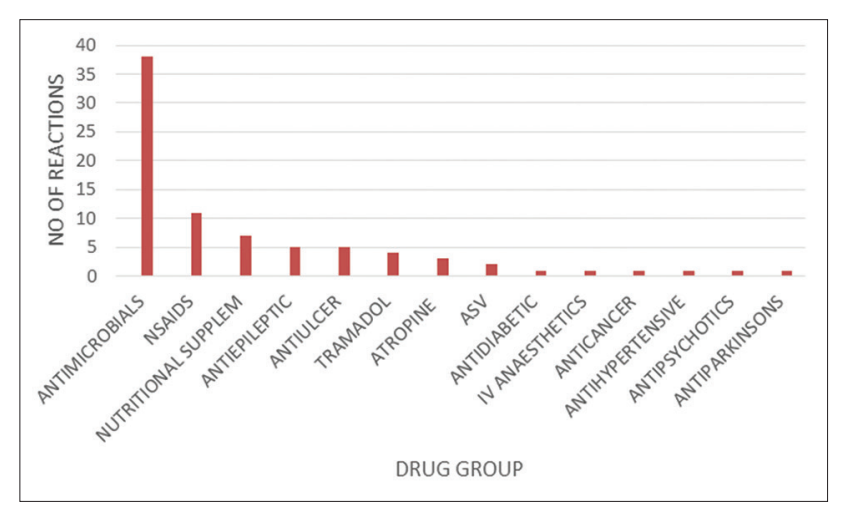

Figure 3: Drug group implicated in adverse drug reactions.

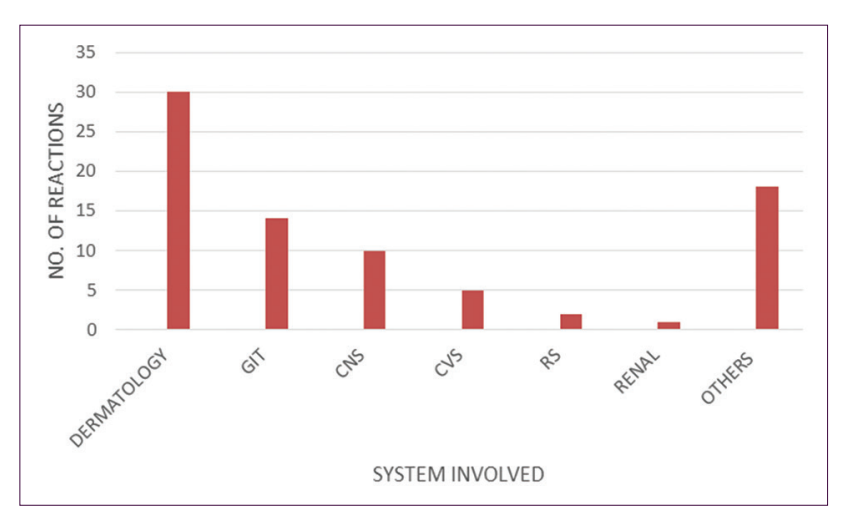

Figure 4: Organ system involved in drug reactions.
Table 2: Management of ADRs.

\begin{tabular}{|lc|}
\hline Treatment & Number $(\%)$ \\
\hline Stopped the medication & $47(58.02)$ \\
\hline Continued the same & $29(35.80)$ \\
\hline Dose reduced & $5(6.17)$ \\
\hline
\end{tabular}

ADR: Adverse drug reaction

are nonserious and the suspected drug was continued when the benefits outweigh the risks and with proper patient counseling (Table 2).

\section{DISCUSSION}

ADR are one of the most common causes of morbidity and mortality all over the world, but they are overlooked by the clinicians most of the times. In India also ADRs have emerged as leading killers. ${ }^{12}$ The foremost objective of PvPI was to facilitate and improve the reporting of ADRs in India and to promote patients' safety. ${ }^{13}$ Establishment of Pharmacovigilance units in the Medical College and hospitals has facilitated the spontaneous reporting of ADRs to a great extent.

The present study was conducted in order to identify the most frequent ADRs occurring in our institution, their nature, causality, severity, and drugs commonly causing these ADRs. In this study, 85 ADRs were reported in 83 patients voluntarily over a period of 1 year by the health care professionals. The spontaneous voluntary reporting of ADRs was adequate in a new ADR monitoring center, and there is a scope for better reporting with increased awareness through regular sensitization programs. The reasons that were identified for under reporting were like busy schedule of the clinicians, lack of incentive, etc.

The demographic analysis showed a predominance of adults over geriatric and pediatric age group. This was in accordance with the previous studies by Patidar et al., ${ }^{12}$ Murphy and Frigo, ${ }^{14}$ and Lobo et al., ${ }^{15}$ but differed from studies carried out by Lin and Lin. ${ }^{16}$ The reason may be higher number of adults visiting the hospital outpatients department or being hospitalized and dose adjustments made in pediatric or geriatric groups. The incidence of ADRs was slightly more in males than in females. This was in accordance with study by Lobo et al. ${ }^{15}$ and Dutta et al. ${ }^{17}$

The most commonly observed ADRs were dermatological type $\mathrm{B}$ reactions. This finding was consistent with other studies which have reported a higher percentage of dermatological manifestations. ${ }^{7,12,17}$ The probable reason for this is the visibility of these ADRs which makes the diagnosis easier. Antimicrobials were the most common drugs causing ADR indicating higher usage of these group of drugs. These findings are consistent with the previous studies by Patidar et al., ${ }^{12}$ Murphy and Frigo, ${ }^{14}$ and Caranasos et al. ${ }^{18}$ Causality assessment was done to further strengthen the validity of findings by using WHO-UMC scale. The majority of the 
ADRs belonged to the possible or probable category, but no reaction was categorized as definite.

The severity assessment was done using Hartwig and Siegel's severity assessment scale. ${ }^{11}$ The majority of the ADRs were nonserious. These findings were in accordance with the study by Lobo et al. ${ }^{15}$ The majority of the patients recovered from the ADRs after appropriate treatment and few patients could not be followed. This is in accordance with the study by Vijayakumar et al.?

\section{Limitations of the study}

The cost incurred in the treatment of ADRs was not analyzed.

\section{CONCLUSION}

Dermatological reactions are the most common ADRs occurring in our hospital and antimicrobials are the most common causative drugs. The reporting rate was good with regular sensitization programs, and there is still a need for increasing the awareness and knowledge about ADR reporting system. Pharmacovigilance program of India is a good success with the involvement of all medical colleges and drug companies. Increasing public awareness against self-medication and possible hazards by using drugs without prescription will lead to reporting of ADR by patients. The patient reporting is made easy by PvPI with the release of medicines side effect reporting form for consumers in different regional languages. Apart from this PvPI is to launch android phone application for ADR reporting that has also been set up and is expected to be functional soon.

The functional ADR monitoring system in a hospital can help to measure ADR incidence rates over a period of time and increase the knowledge of health care professionals about the drug effects and improve risk management activities to ADRs. An effective Pharmacovigilance program can ensure quality, safe and focused care to patients by providing drug safety information to physicians and to regulatory authorities for prompt and appropriate action.

\section{ACKNOWLEDGMENTS}

We acknowledge all the clinical departments of Kamineni Institute of Medical Sciences Hospital, Narketpally for their cooperation for voluntary reporting of ADR.

\section{Funding: No funding sources}

Conflict of interest: None declared

Ethical approval: The study was approved by the Institutional Ethics Committee

\section{REFERENCES}

1. World Health Organization. International drug monitoring: the role of the hospital. In Technical report series no. 425 .
Geneva, Switzerland: World Health Organization; 1969: 1-24. Available at: http://www.whqlibdoc.who.int/trs/ WHO_TRS_425.pdf. Accessed 22 March 2015

2. Lazarou J, Pomeranz BH, Corey PN. Incidence of adverse drug reactions in hospitalized patients: a meta-analysis of prospective studies. JAMA. 1998;279(15):1200-5.

3. Meyboom RH, Lindquist M, Egberts AC, Edwards IR. Signal selection and follow-up in pharmacovigilance. Drug Saf. 2002;25(6):459-65.

4. Pirmohamed M, Breckenridge AM, Kitteringham NR, Park BK. Adverse drug reactions. BMJ. 1998;316:1295-8.

5. Swamy S, Bhanuprakash, Nadig P, Muralimohan, Shetty M. Profile of suspect adverse drug reactions in a teaching tertiary care hospital. J Pharmacol Clin Toxicol. 2013;1(1):1005.

6. Arulmani R, Rajendran SD, Suresh B. Adverse drug reaction monitoring in a secondary care hospital in South India. Br J Clin Pharmacol. 2008;65(2):210-6.

7. Vijayakumar TM, Dhanaraju MD. Description of adverse drug reactions in a multi-speciality teaching hospital. Int $\mathbf{J}$ Integr Med. 2013;1(26):1-6.

8. Pharmacovigilance Programme of India. CDSCO, Ministry of Health and Family Welfare, Government of India. Ghaziabad: Pharmacovigilance Programme of India; 2010

9. The use of the WHO-UMC system for standardised case causality assessment. Available at: http://www.who-umc. org/Graphics/24734.pdf. Accessed 02 October 2013.

10. Rawlins MD, Thomson JW. Mechanisms of adverse drug reactions. In Davies DM, editor. Textbook of Adverse Reactions. New York: Oxford University Press; 1991: 18-45.

11. Hartwig SC, Siegel J, Schneider PJ. Preventability and severity assessment in reporting adverse drug reactions. Am J Hosp Pharm. 1992;49(9):2229-32.

12. Patidar D, Rajput MS, Nirmal NP, Savitri W. Implementation and evaluation of adverse drug reaction monitoring system in a tertiary care teaching hospital in Mumbai, India. Interdiscip Toxicol. 2013;6(1):41-6.

13. Pharmacovigilance programme of India (PvPI). Newsletter. 2014;4(10):1-16.

14. Murphy BM, Frigo LC. Development, implementation, and results of a successful multidisciplinary adverse drug reaction reporting program in a university teaching hospital. Hosp Pharm. 1993;28(12):1199-204, 1240.

15. Lobo MG, Pinheiro SM, Castro JG, Momenté VG, Pranchevicius MC. Adverse drug reaction monitoring: support for pharmacovigilance at a tertiary care hospital in Northern Brazil. BMC Pharmacol Toxicol. 2013;14:5.

16. Lin SH, Lin MS. A survey on drug-related hospitalization in a community teaching hospital. Int J Clin Pharmacol Ther Toxicol. 1993;31(2):66-9.

17. Dutta SB, Beg MA, Bawa S, Anjoom M, Varma A, Singh NK, et al. A retrospective analysis of adverse drug reactions in a tertiary care teaching hospital at Dehradun, Uttarakhand. Int J Basic Clin Pharmacol. 2015;4(1):121-4.

18. Caranasos GJ, Stewart RB, Cluff LE. Drug-induced illness leading to hospitalization. JAMA. 1974;228(6):713-7.

Cite this article as: Shareef SM, Naidu CDM, Raikar SR, Rao YV, Devika U. Development, implementation and analysis of adverse drug reaction monitoring system in a rural tertiary care teaching hospital in Narketpally, Telangana. Int J Basic Clin Pharmacol 2015;4:757-60. 